\title{
Short time horizons for fracture prediction tools: time for a rethink
}

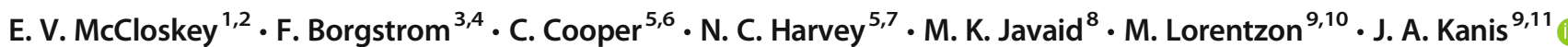

Received: 9 February 2021 / Accepted: 13 April 2021 / Published online: 29 April 2021

(C) International Osteoporosis Foundation and National Osteoporosis Foundation 2021

\section{Prior fracture increases risk of future fracture in a time-dependent manner}

Prior fragility fracture is a well-established risk factor for a future fracture [1-4]. The population relative risk of having a subsequent hip fracture or other osteoporotic fracture is approximately 2-fold higher for most types of prior fracture. However, many studies suggest that the increase in risk is not constant with time or age. Indeed, the risk of a subsequent osteoporotic fracture is particularly acute immediately after an index fracture and wanes progressively over the next 2 years [4-9] but thereafter remains higher than that of the general population (Fig. 1 ). The early phase of particularly high risk has been termed imminent risk [9]. This transiency, which is not currently accommodated in any of the available fracture risk assessment tools, suggests that treatment given to patients immediately after a fracture might avoid a higher number of new fractures compared with treatment given at a later date.

\section{Determinants of short-term risk also determine long-term risk}

Confusion has arisen, however, about the use of the term imminent risk which has been variously used to imply a transient high risk or simply a high risk in the short term, regardless of transiency. Irrespective of its description, the view has arisen for the need for shorter timeframes over which to express fracture risk. This is illustrated by a number of studies, many of them recently published

\section{J. A. Kanis}

w.j.pontefract@shef.ac.uk

E. V. McCloskey

e.v.mccloskey@sheffield.ac.uk

F. Borgstrom

fredrik.borgstrom@quantifyresearch.com

C. Cooper

cc@mrc.soton.ac.uk

N. C. Harvey

nch@mrc.soton.ac.uk

M. K. Javaid

kassim.javaid@ndorms.ox.ac.uk

M. Lorentzon

mattias.lorentzon@medic.gu.se

1 Centre for Metabolic Bone Diseases, University of Sheffield, Sheffield, UK

2 MRC Versus Arthritis Centre for Integrated Research in Musculoskeletal Ageing, Mellanby Centre for Musculoskeletal Research, University of Sheffield, Sheffield, UK
Quantify Research, Stockholm, Sweden

4 Department of Learning, Informatics, Management and Ethics (LIME), Karolinska Institutet, Stockholm, Sweden

5 MRC Lifecourse Epidemiology Unit, University of Southampton, Southampton, UK

6 NIHR Musculoskeletal Biomedical Research Unit, University of Oxford, Oxford, UK

7 NIHR Southampton Biomedical Research Centre, University of Southampton and University Hospital Southampton NHS Foundation Trust, Southampton, UK

$8 \quad$ Nuffield Department of Orthopaedics, Rheumatology and Musculoskeletal Sciences, University of Oxford, Oxford, UK

9 Mary McKillop Institute for Health Research, Australian Catholic University, Melbourne, Australia

10 Geriatric Medicine, Institute of Medicine, Sahlgrenska Academy, University of Gothenburg, Gothenburg, Sweden

11 Centre for Metabolic Bone Diseases, University of Sheffield Medical School, Beech Hill Road, Sheffield S10 2RX, UK 


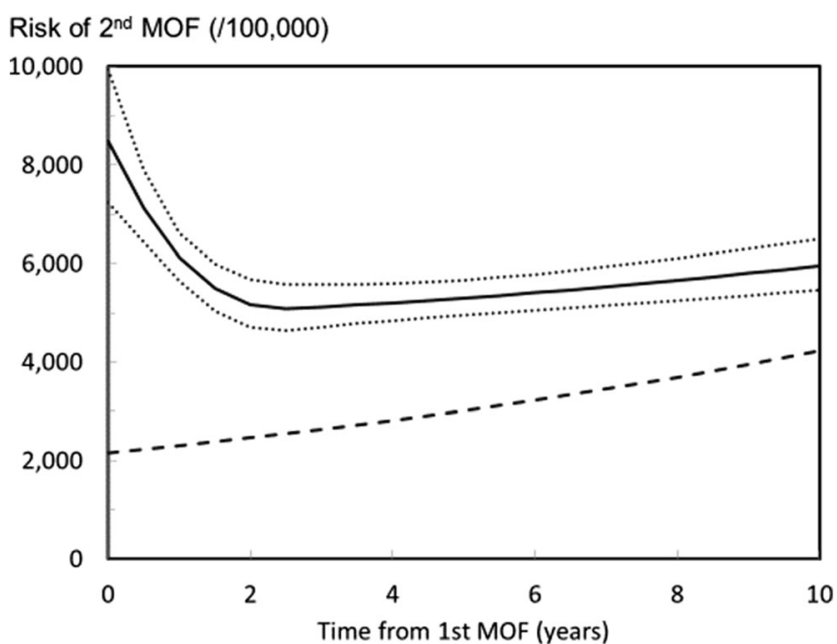

Fig. 1 Risk per 100,000 (95\% CI) of a second major osteoporotic fracture (MOF) after a first MOF for a woman at the age of 75 years at her first fracture. Knots for the spline function are set at 0.5, 2.5 and 15 years of follow-up after the first fracture. The dashed line is the risk of first MOF in the whole population $(n=18,872)$ for a woman 75 years at baseline [9] (with kind permission from Springer Science+Business Media B.V)

(Table 1), that seek to identify risk factors associated with incident fractures over a short time horizon, usually up to 2 years after a sentinel fracture. Some derive associated risk prediction algorithms, and, as expected, many of these studies confirm an increased fracture risk associated with a prior fracture, but in many, the mean absolute risk at 2 years is low $(<10 \%)$, while in others that considered patients with recent fractures, the mean absolute risks were still around $10-15 \%$ (see Table 1). Apart from the known heterogeneity of fracture risk between countries [31], a source of heterogeneity may be the site of index fracture which in turn will be age-dependent [32]. In addition, some of the latter studies showed no convincing evidence of imminency of risk in that the relative risk at 2 years is no greater than the relative risk at 5 years $[14,27$, 29].

\section{Shorter time horizons yield lower magnitude absolute fracture risks}

The rationale behind the need to express fracture risk over a 2-year time horizon as opposed to a longer term to determine intervention requires examination. The most lucid arguments state that tools such as FRAX predict risk over the long term and do not explicitly provide shortterm risk estimates necessary to identify patients likely to experience a fracture in the next $1-2$ years [10]. This logic implies that there are special characteristics in individuals at high short-term fracture risk not shared by those at long-term risk [33]. There is however no evidence that risk factors for short-term recurrent fractures differ from those identified for fracture irrespective of the time horizon [12-14, 17, 21, 25, 34-37] though this is not easily assessed in studies using machine-learning techniques where the drivers of risk remain opaque [38]. Moreover, a plethora of studies indicates that a heightened risk at 1 or 2 years persists for 5 to 10 years after the event $[6,8$, 11, 14-16, 23, 27, 29, 39] (see Table 1). In other words, a high short-term risk aligns with a very high longer-term risk. Thus, the sole impact of choosing a 1- or 2-year time horizon is to decrease the magnitude of the absolute risk estimate produced by the algorithm (to oversimplify, e.g. a 10-year risk of fracture of $50 \%$ can be expressed as a 1year risk of 5\%). The oversimplification is that the relationship between time horizon and fracture risk is not linear [39] (Fig. 2). For example, in women with a prior fracture, the ratio between the 10- and 2-year probabilities is much smaller at older ages than younger ages; for example, at the age of 50 years, the 10 -year probability is 8 times the 2-year probability, whereas at the age of 90 , the ratio is $2.3: 1$. Note that neither of these ratios is $5: 1$, reflecting the non-linear relationships of fracture risk and death risk with age. For a 5-year timeframe, the respective ratios to 10-year probabilities are 3:1 and 1.25:1 at the same ages. The lower ratios at older ages are particularly important to appreciate and arise because the 10-year probability is calculated by taking into account the risk of fracture and the risk of death. As the latter exceeds the former at very old age, the probability of fracture actually decreases while remaining high, and the 10-year probability approaches the 2-year and 5-year probabilities (Fig. 2). At these advanced ages, the tool is calculating a 'remaining life-time' risk of fracture and, indeed, can usefully be expressed to patients and their carers in this way.

Given the difficulty that many patients (and indeed healthcare professionals) have in the interpretation of risk, being presented with a fracture risk which is low simply because it is over 2 years, may well be rather less convincing with regard to the need to commence treatment, compared with a substantially larger value pertaining to a 10 year time horizon. Despite a large literature on communication of risk [40, 41], there is relatively little empirical information on the optimal time horizon for expressing risk. The available information would suggest that longer rather than shorter time horizons are preferred in postmenopausal women [41, 42].

\section{Adjusting 10-year probability to account for fracture recency}

As stated previously, none of the current fracture risk calculators take account of the heightened fracture risk 


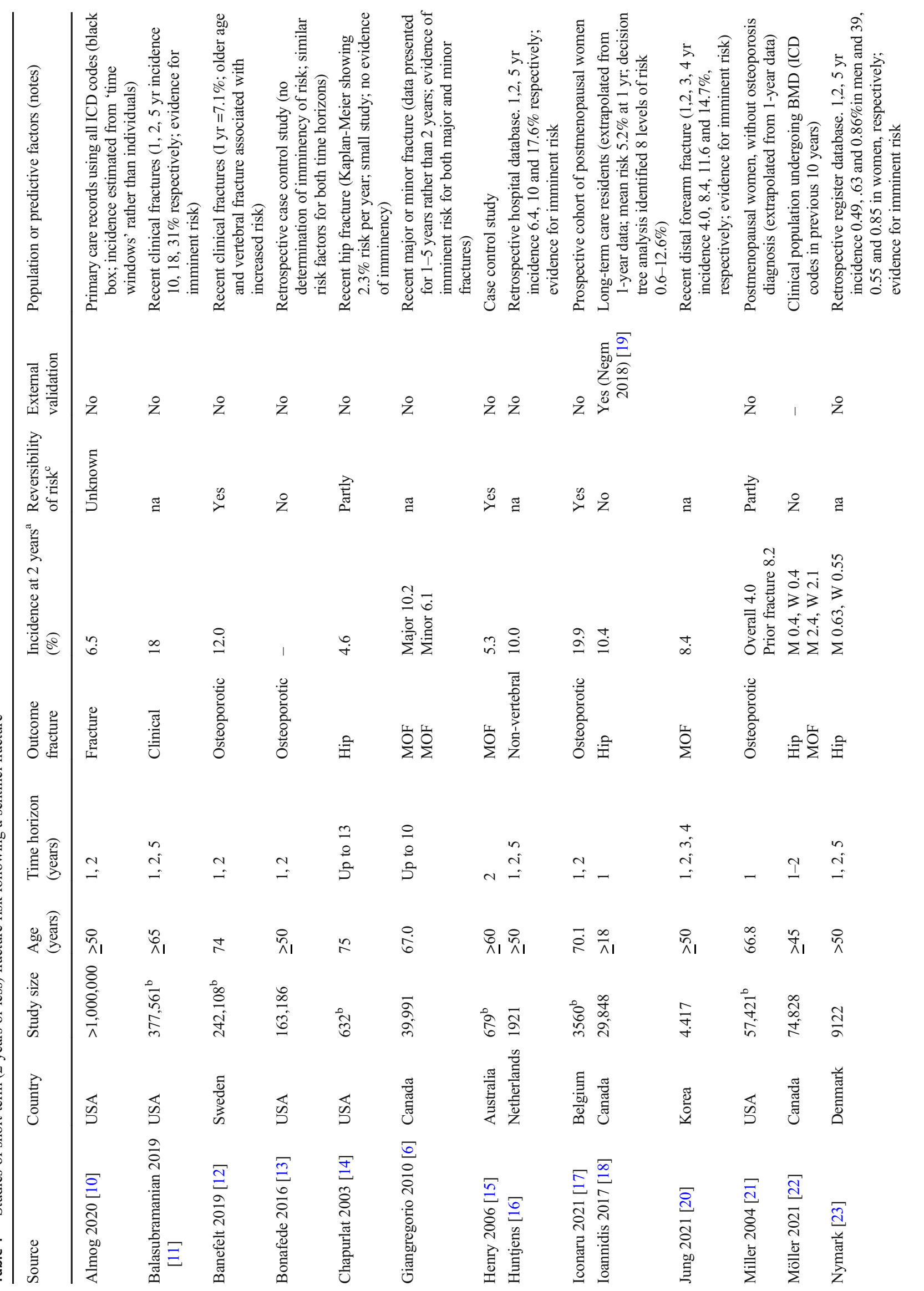




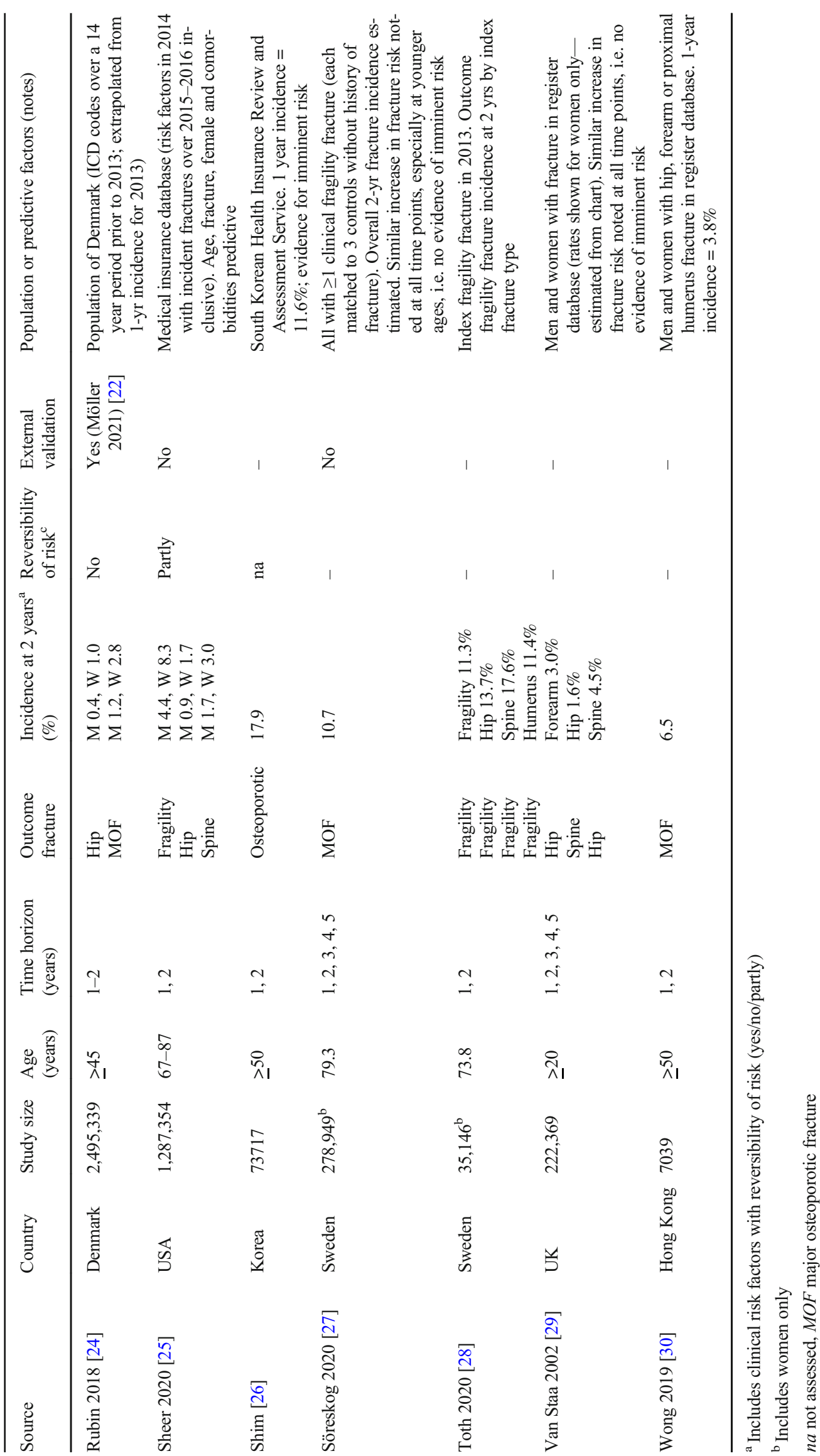


Fig. 2 Probabilities of a major osteoporotic fracture (MOF) in Icelandic women with a prior fracture (of any recency) by age and time horizon [39] (with kind permission from Springer Science+Business Media B.V)

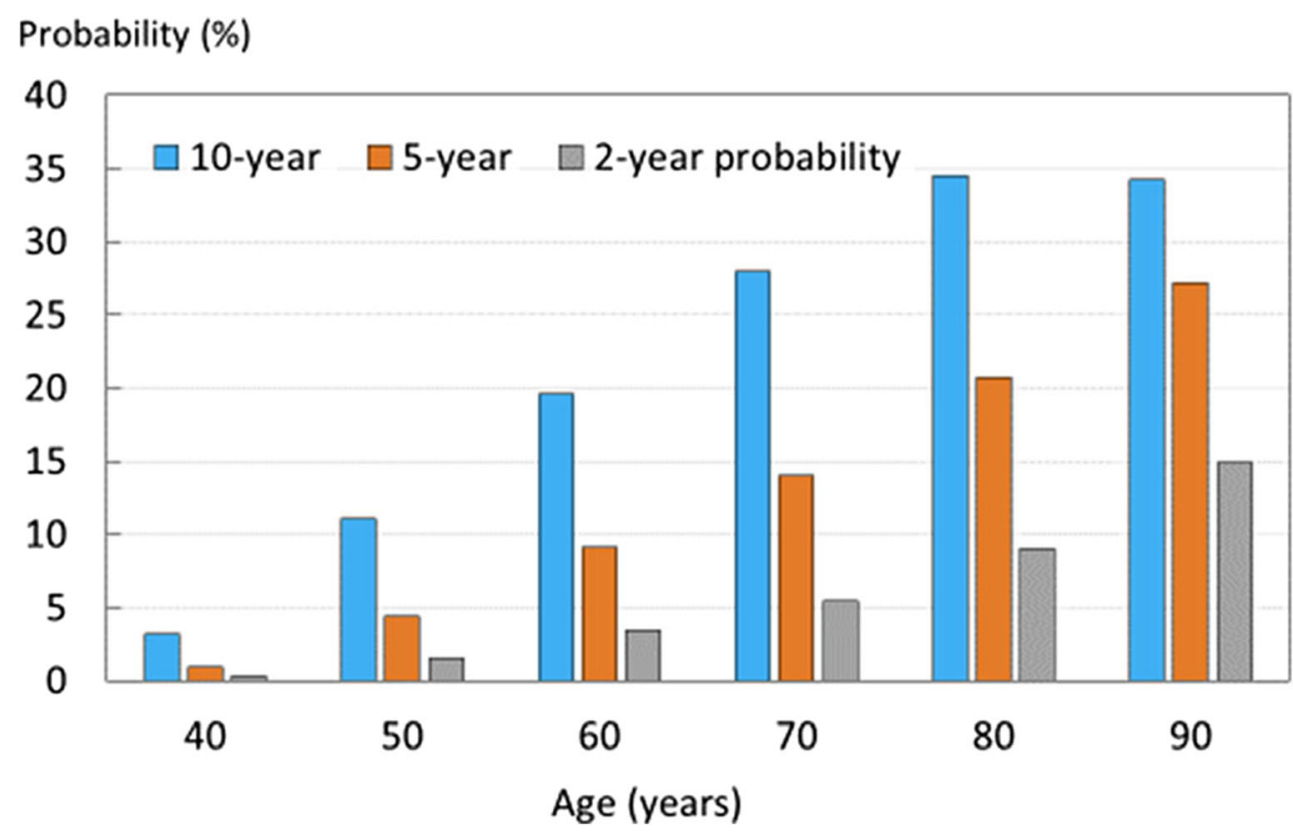

associated with a recent major osteoporotic fracture. However, recent analyses demonstrate that estimates of 10-year fracture probability derived from the FRAX tool can be adjusted according to the recency and site of sentinel fractures; this is shown for the outcome of major osteoporotic fracture in Table 2 [43]. For example, a woman age 70 years from the UK with a prior fragility fracture and no other clinical risk factors has a $20 \% 10$ year fracture probability for a major osteoporotic fracture calculated with FRAX. Where the prior fracture was recent (within 2 years) and was a clinical spine fracture, the adjusted fracture probability would be upward adjusted to $30 \%(20 \times 1.50)$. Thus, many but not all such adjustments substantially increase fracture probability and could change the category of risk from high to very high, depending on the thresholds selected, and thereby merit consideration of anabolic interventions [44].

\section{Summary and conclusion}

Multiple studies of short-term fracture risk have identified similar risk factors to those already well-established in fracture prediction tools over the longer term. High shortterm risk is usually associated with a very high long-term risk. Although tools that calculate short-term risk may be superficially attractive, the substantially lower absolute risk generated compared with a 10 -year time horizon and the absence of guidelines through which to interpret these outputs are clear limitations to their use in clinical practice. In contrast, the uplift in risk arising from recent discrete events such as fracture can be readily accommodated in FRAX over a 10-year time horizon and linked to established national intervention thresholds that are already widely embedded in clinical guidelines for the management of osteoporosis. That very high risk requires rapid and effective intervention, with combinations or sequences
Table 2 Multipliers for the adjustment of conventional estimates of 10-year probability of a major osteoporotic fracture for a recent fracture (within 2 years) in men and women at the sites shown [43]

\begin{tabular}{|c|c|c|c|c|c|c|c|c|}
\hline \multirow[t]{2}{*}{ Age (years) } & \multicolumn{2}{|l|}{ Spine } & \multicolumn{2}{|l|}{ Hip } & \multicolumn{2}{|c|}{ Humerus } & \multicolumn{2}{|c|}{ Forearm } \\
\hline & Men & Women & Men & Women & Men & Women & Men & Women \\
\hline 40 & 4.18 & 7.14 & 5.31 & 6.77 & 3.08 & 4.79 & 2.61 & 3.53 \\
\hline 50 & 1.92 & 2.62 & 2.28 & 2.38 & 1.56 & 1.96 & 1.33 & 1.46 \\
\hline 60 & 1.57 & 1.84 & 1.73 & 1.60 & 1.42 & 1.54 & 1.23 & 1.16 \\
\hline 70 & 1.48 & 1.50 & 1.46 & 1.23 & 1.45 & 1.39 & 1.33 & 1.09 \\
\hline 80 & 1.24 & 1.23 & 1.08 & 0.95 & 1.25 & 1.26 & 1.22 & 1.01 \\
\hline 90 & 0.89 & 1.01 & 0.72 & 0.74 & 0.85 & 1.08 & 0.80 & 0.81 \\
\hline
\end{tabular}


of pharmacological approaches and/or physical interventions (e.g. falls risk reduction), which is also easily appreciated.

\section{Declarations}

Conflicts of interests JAK, NCH, ML and EVM are responsible for the creation and maintenance of FRAX but derive no financial benefit. EVM has received consultancy/lecture fees/grant funding/honoraria from AgNovos, Amgen, AstraZeneca, Consilient Healthcare, Fresenius Kabi, Gilead, GSK, Hologic, Internis, Lilly, Merck, Novartis, Pfizer, Radius Health, Redx Oncology, Roche, Sanofi Aventis, UCB, ViiV, Warner Chilcott and I3 Innovus. FB is employed by and is a shareholder of Quantify Research, a health economic research consultancy. CC reports personal fees from Alliance for Better Bone Health, Amgen, Eli Lilly, GSK, Medtronic, Merck, Novartis, Pfizer, Roche, Servier, Takeda and $\mathrm{UCB}$. NCH has received consultancy/lecture fees/honoraria/grant funding from Alliance for Better Bone Health, Amgen, MSD, Eli Lilly, Radius Health, Servier, Shire, UCB, Consilient Healthcare and Internis Pharma. MKJ declares no conflicts of interest. ML has received lecture fees from Amgen, Lilly, Meda, Renapharma and UCB Pharma and consulting fees from Amgen, Radius Health, UCB Pharma, Renapharma and Consilient Health, all outside the presented work. JAK reports no additional competing interests.

\section{References}

1. Klotzbuecher CM, Ross PD, Landsman PB, Abbott TA 3rd, Berger $M$ (2000) Patients with prior fractures have an increased risk of future fractures: a summary of the literature and statistical synthesis. J Bone Miner Res 15:721-739

2. Haentjens P, Johnell O, Kanis JA, Bouillon R, Cooper C, Lamraski G, Vanderschuren D, Kauffman J-M, Boonen S (2004) Genderrelated differences in short and long-term absolute risk of hip fracture after Colles' or spine fracture: Colles' fracture as an early and sensitive marker of skeletal fragility in men. J Bone Miner Res 19: 1933-1944

3. Johnell O, Kanis JA, Oden A, Sernbo I, Redlund-Johnell I, Pettersen C, De Laet C, Jonsson B (2004) Fracture risk following an osteoporotic fracture. Osteoporos Int 15:175-179

4. Kanis JA, Johnell O, De Laet C, Johansson H, Oden A, Delmas P, Eisman J, Fujiwara S, Garnero P, Kroger H, McCloskey EV, Mellstrom D, Melton LJ III, Pols H, Reeve J, Silman A, Tenenhouse A (2004) A meta-analysis of previous fracture and subsequent fracture risk. Bone 35:375-382

5. Johnell O, Oden A, Caulin F, Kanis JA (2001) Acute and long-term increase in fracture risk after hospitalization for vertebral fracture. Osteoporos Int 12:207-214

6. Giangregorio LM, Leslie WD, Manitoba Bone Density Program (2010) Time since prior fracture is a risk modifier for 10-year osteoporotic fractures. J Bone Miner Res 25:1400-1405

7. Ryg J, Rejnmark L, Overgaard S, Brixen K, Vestergaard P (2009) Hip fracture patients at risk of second hip fracture: a nationwide population-based cohort study of 169,145 cases during 1977-2001. J Bone Miner Res 24:1299-1307

8. van Geel TA, van Helden S, Geusens PP, Winkens B, Dinant GJ (2009) Clinical subsequent fractures cluster in time after first fractures. Ann Rheum Dis 68:99-102

9. Johansson H, Siggeirsdóttir K, Harvey NC, Odén A, Gudnason V, McCloskey E, Sigurdsson G, Kanis JA (2017) Imminent risk of fracture after fracture. Osteoporos Int 28:775-780
10. Almog YA, Rai A, Zhang P, Moulaison A, Powell R, Mishra A, Weinberg K, Hamilton C, Oates M, McCloskey E (2020) Cummings SR (2020) Deep learning with electronic health records for short-term fracture risk identification: crystal bone algorithm development and validation. J Med Internet Res 22(10):e22550. https://doi.org/10.2196/22550

11. Balasubramanian A, Zhang J, Chen L, Wenkert D, Daigle SG, Grauer A, Curtis JR (2019) Risk of subsequent fracture after prior fracture among older women. Osteoporos Int 30:79-92

12. Banefelt J, Åkesson KE, Spångéus A, Ljunggren O, Karlsson L, Ström O, Ortsäter G, Libanati C, Toth E (2019) Risk of imminent fracture following a previous fracture in a Swedish database study. Osteoporos Int 30:601-609

13. Bonafede M, Shi N, Barron R, Li X, Crittenden DB, Chandler D (2016) Predicting imminent risk for fracture in patients aged 50 or older with osteoporosis using US claims data. Arch Osteoporos 11(1):26. https://doi.org/10.1007/s11657-016-0280-5

14. Chapurlat RD, Bauer DC, Nevitt M, Stone K, Cummings SR (2003) Incidence and risk factors for a second hip fracture in elderly women. The Study of Osteoporotic Fractures. Osteoporos Int 14: $130-136$

15. Henry MJ, Pasco JA, Sanders KM, Nicholson GC, Kotowicz MA (2006) Fracture risk (FRISK) score: Geelong osteoporosis study. Radiology 241:190-196

16. Huntjens KM, Kosar S, van Geel TA, Geusens PP, Willems P, Kessels A, Winkens B, Brink P, van Helden S (2010) Risk of subsequent fracture and mortality within 5 years after a nonvertebral fracture. Osteoporos Int 21:2075-2082

17. Iconaru L, Moreau M, Baleanu F, Kinnard V, Charles A, Mugisha A, Surquin M, Benoit F, Karmali R, Paesmans M, Body JJ, Bergmann P (2021) Risk factors for imminent fractures: a substudy of the FRISBEE cohort. Osteoporos Int. https://doi.org/10.1007/ s00198-020-05772-8

18. Ioannidis G, Jantzi M, Bucek J, Adachi JD, Giangregorio L, Hirdes J, Pickard L, Papaioannou A (2017) Development and validation of the Fracture Risk Scale (FRS) that predicts fracture over a 1-year time period in institutionalised frail older people living in Canada: an electronic record-linked longitudinal cohort study. BMJ Open 7(9):e016477. https://doi.org/10.1136/bmjopen-2017-016477

19. Negm AM, Ioannidis G, Jantzi M, Bucek J, Giangregorio L, Pickard L, Hirdes JP, Adachi JD, Richardson J, Thabane L, Papaioannou A (2018) Validation of a one year fracture prediction tool for absolute hip fracture risk in long term care residents. BMC Geriatr 18(1):320. https://doi.org/10.1186/s12877-018-1010-1

20. Jung HS, Jang S, Chung HY, Park SY, Kim HY, Ha YC, Lee YK, Nho JH (2021) Incidence of subsequent osteoporotic fractures after distal radius fractures and mortality of the subsequent distal radius fractures: a retrospective analysis of claims data of the Korea National Health Insurance Service. Osteoporos Int 32:293-299

21. Miller PD, Barlas S, Brenneman SK, Abbott TA, Chen YT, BarrettConnor E, Siris ES (2004) An approach to identifying osteopenic women at increased short-term risk of fracture. Arch Intern Med 164:1113-1120

22. Möller S, Skjødt MK, Yan L, Abrahamsen B, Lix LM, McCloskey EV, Johansson H, Harvey NC, Kanis JA, Rubin KH, Leslie WD (2020) Prediction of imminent fracture risk in Canadian women and men aged 45 years or older: external validation of the Fracture Risk Evaluation Model. J Bone Miner Res. Submitted Jan 2021

23. Nymark T, Lauritsen JM, Ovesen O, Röck ND, Jeune B (2006) Short timeframe from first to second hip fracture in the Funen County Hip Fracture Study. Osteoporos Int 17:1353-1357

24. Rubin KH, Möller S, Holmberg T, Bliddal M, Søndergaard J, Abrahamsen B (2018) A new fracture risk assessment tool (FREM) based on public health registries. J Bone Miner Res 33: 1967-1979 
25. Sheer RL, Barron RL, Sudharshan L, Pasquale MK (2020) Validated prediction of imminent risk of fracture for older adults. Am J Manag Care 26:e91-e97. https://doi.org/10.37765/ajmc. 2020.42641

26. Shim YB, Park JA, Nam JH, Hong SH, Kim JW, Jeong J, Shin JY (2020) Incidence and risk factors of subsequent osteoporotic fracture: a nationwide cohort study in South Korea. Arch Osteoporos 15(1):180. https://doi.org/10.1007/s11657-020-00852-y

27. Söreskog E, Ström O, Spångéus A, Åkesson KE, Borgström F, Banefelt J, Toth E, Libanati C, Charokopou M (2020) Risk of major osteoporotic fracture after first, second and third fracture in Swedish women aged 50 years and older. Bone 134:115286. https://doi.org/ 10.1016/j.bone.2020.115286

28. Toth E, Banefelt J, Åkesson K, Spångeus A, Ortsäter G, Libanati C (2020) History of previous fracture and imminent fracture risk in Swedish women aged 55 to 90 years presenting with a fragility fracture. J Bone Miner Res 35:861-868

29. van Staa TP, Leufkens HG, Cooper C (2002) Does a fracture at one site predict later fractures at other sites? A British cohort study. Osteoporos Int 13:624-629

30. Wong RMY, Ho WT, Wai LS, Li W, Chau WW, Chow KS, Cheung WH (2019) Fragility fractures and imminent fracture risk in Hong Kong: one of the cities with longest life expectancies. Arch Osteoporos 14(1):104. https://doi.org/10.1007/s11657-019-0648-4

31. Kanis JA, Odén A, McCloskey EV, Johansson H, Wahl D, Cyrus Cooper $\mathrm{C}$ on behalf of the IOF Working Group on Epidemiology and Quality of Life (2012) A systematic review of hip fracture incidence and probability of fracture worldwide. Osteoporos Int 23:2239-2256

32. Kanis JA, Johansson H, Harvey NC, Gudnason V, Sigurdsson G, Siggeirsdottir K, Lorentzon M, Liu E, Vandenput L, McCloskey EV (2021) The effect on subsequent fracture risk of age, sex, and prior fracture site by recency of prior fracture. Osteoporos Int. https://doi.org/10.1007/s00198-020-05803-4

33. Deloumeau A, Moltó A, Roux C, Briot K (2017) Determinants of short term fracture risk in patients with a recent history of lowtrauma non-vertebral fracture. Bone 105:287-291. https://doi.org/ 10.1016/j.bone.2017.08.018

34. Adachi JD, Berger C, Barron R, Weycker D, Anastassiades TP, Davison KS, Hanley DA, Ioannidis G, Jackson SA, Josse RG, Kaiser SM, Kovacs CS, Leslie WD, Morin SN, Papaioannou A, Prior JC, Shyta E, Silvia A, Towheed T, Goltzman D (2019) Predictors of imminent nonvertebral fracture in elderly women with osteoporosis, low bone mass, or a history of fracture, based on data from the population based Canadian Multicentre Osteoporosis Study (CaMos). Arch Osteoporos 4(1):53. https://doi.org/10.1007/ s11657-019-0598-x
35. Hannan MT, Weycker D, McLean RR, Sahni S, Bornheimer R, Barron R, Travison TG, Kiel DP (2019) Predictors of imminent risk of nonvertebral fracture in older, high-risk women: the Framingham Osteoporosis Study. JBMR Plus 3(6):e10129. https://doi.org/10.1002/jbm4.10129

36. Chen YT, Miller PD, Barrett-Connor E, Weiss TW, Sajjan SG, Siris ES (2007) An approach for identifying postmenopausal women age 50-64 years at increased short-term risk for osteoporotic fracture. Osteoporos Int 18:1287-1296

37. Weycker D, Edelsberg J, Barron R, Atwood M, Oster G, Crittenden DB, Grauer A (2017) Predictors of near-term fracture in osteoporotic women aged $\geq 65$ years, based on data from the study of osteoporotic fractures. Osteoporos Int 28:2565-2571

38. Hans D, Shevroja E, Leslie WD (2021) Evolution in fracture risk assessment: artificial versus augmented intelligence. Osteoporos Int 32:209-212

39. Kanis JA, Johansson H, Harvey NC, Gudnason V, Sigurdsson G, Siggeirsdottir K, Lorentzon M, Liu M, Vandenput L, McCloskey E (2021) The use of two-, five- and 10-year probabilities to characterise fracture risk after a recent sentinel fracture. Osteoporos Int 32: $47-54$

40. Trevena L (2004) Assessing, communicating, and managing risk in general practice. Br J Gen Pract 64:166-167

41. Epstein RM, Alper BS, Quill TE (2004) Communicating evidence for participatory decision making. JAMA 291:2359-2366

42. Fortin JM, Hirota LK, Bond BE, O'Connor AM, Col NF (2001) Identifying patient preferences for communicating risk estimates: a descriptive pilot study. BMC Med Inform Decis Mak 1:2. https:// doi.org/10.1186/1472-6947-1-2

43. Kanis JA, Johansson H, Harvey NC, Gudnason V, Sigurdsson G, Siggeirsdottir K, Lorentzon M, Liu E, Vandenput L, McCloskey EV (2020) Adjusting conventional FRAX estimates of fracture probability according to the recency of sentinel fractures. Osteoporos 31:1817-1828

44. Kanis JA, Harvey NC, McCloskey E, Bruyère O, Veronese N, Lorentzon M, Cooper C, Rizzoli R, Adib G, Al-Daghri N, Campusano C, Chandran M, Dawson-Hughes B, Javaid K, Jiwa FF, Johansson H, Lee JK, Liu E, Messina D, Mkinsi O, Pinto D, Prieto-Alhambra D, Saag K, Xia W, Zakraoui L, Reginster J-Y (2020) Algorithm for the management of patients at low/middle/ high risk of osteoporotic fracture: a global perspective. Osteoporos Int 31:1-12

Publisher's note Springer Nature remains neutral with regard to jurisdictional claims in published maps and institutional affiliations. 